\title{
Isolated neonatal sclerosing cholangitis
}

INSERM

\section{Source}

INSERM. (1999). Orphanet: an online rare disease and orphan drug data base. Isolated neonatal sclerosing cholangitis. ORPHA:480556

Isolated neonatal sclerosing cholang itis is a rare, genetic, biliary tract disease characterized by severe neonatal-onset cholangiopathy with patent bile ducts and absence of ichthyosiform skin lesions. Patients present with jaundice, acholic stools, hepatosplenomeg aly and high serum gamma-glutamyltransferase activity. Liver histology shows portal fibrosis, ductular proliferation, hepatocellular metallothionein deposits, and intralobular bile-pigment accumulations. Some patients may also have renal disease. 